\title{
Peripheral oxygen saturation to inspiratory oxygen fraction ratio-based identification of critically ill coronavirus disease patients for early therapeutic interventions
}

\author{
Masaru Shimizu $^{1}$ (D) $\cdot$ Satoru Hashimoto ${ }^{2}$ \\ Received: 4 January 2021 / Accepted: 9 August 2021 / Published online: 15 August 2021 \\ (c) Japanese Society of Anesthesiologists 2021
}

\begin{abstract}
Background Early identification of critically ill coronavirus disease (COVID-19) patients in clinical settings is crucial in reducing the mortality rate. Therefore, this study aimed to determine whether the saturation of peripheral oxygen $\left(\mathrm{SpO}_{2}\right)$ to fraction of inspiratory oxygen $\left(\mathrm{FiO}_{2}\right)$ ratio (SF ratio) at admission is useful for the early identification of severe COVID-19. Methods This single-center, retrospective, observational study conducted at the University Hospital, Kyoto, Japan, included 26 patients diagnosed with COVID-19 between January 24 and May 6, 2020. COVID-19 severity was classified into two groups based on the SF ratio: $\leq 235$ (moderate to severe disease: low group) and $>235$ (normal to mild disease: high group). The characteristics, laboratory data, and outcomes of the patients were examined retrospectively and compared between the groups.

Results Of the 26 patients [median age 51.5 years, interquartile range 35.8-67.0], 6 were in the low group (23\%) and 20 in the high group $(77 \%)$. The low group had a higher respiratory rate than the high group $(p<0.05)$. Blood tests immediately after admission showed that the low group had significantly lower albumin $(p<0.01)$, and higher lactate dehydrogenase $(p<0.01)$, C-reactive protein $(p<0.01)$, and D-dimer $(p<0.01)$ levels than the high group. Moreover, all patients received antiviral agents; four received continuous renal replacement therapy and invasive positive pressure ventilation, one received extracorporeal membrane oxygenation, and two died in the low group.

Conclusion SF ratio measurement at admission could assist clinicians in the early identification of severe COVID-19, which in turn can lead to early therapeutic interventions.
\end{abstract}

Keywords COVID-19 $\cdot \mathrm{SpO}_{2} / \mathrm{FiO}_{2} \cdot \mathrm{SF}$ ratio $\cdot$ Severity $\cdot$ Early identification

\begin{tabular}{|c|c|c|c|c|}
\hline \multicolumn{3}{|c|}{ Abbreviations } & $\mathrm{ICU}$ & Intensive care unit \\
\hline \multicolumn{2}{|c|}{ Alb } & Albumin & $\mathrm{LDH}$ & Lactate dehydrogenase \\
\hline \multicolumn{2}{|c|}{ ALT } & Alanine transaminase & MERS & Middle East respiratory syndrome \\
\hline \multicolumn{2}{|c|}{ AST } & Aspartate transaminase & $\mathrm{PaO} 2$ & Partial pressure of oxygen \\
\hline \multicolumn{2}{|c|}{ BUN } & Blood urea nitrogen & SARS & Severe acute respiratory syndrome \\
\hline \multicolumn{2}{|c|}{ COVID-19 } & Coronavirus disease & $\mathrm{SpO} 2$ & Saturation of peripheral oxygen \\
\hline \multicolumn{2}{|c|}{ CRP } & C-reactive protein & & \\
\hline \multicolumn{2}{|c|}{$\mathrm{CT}$} & Computed tomography & & \\
\hline \multicolumn{2}{|c|}{$\mathrm{FiO} 2$} & Fraction of inspiratory oxygen & \multicolumn{2}{|c|}{ Introduction } \\
\hline$凶$ & $\begin{array}{l}\text { Masaru Shimizu } \\
\text { masaru@koto.kpu-m.ac.jp }\end{array}$ & $\begin{array}{l}\text { imizu } \\
\text { oto.kpu-m.ac.jp }\end{array}$ & \multirow{3}{*}{\multicolumn{2}{|c|}{$\begin{array}{l}\text { Coronavirus disease (COVID-19) is highly infectious, with } \\
\text { a high mortality rate among severe cases. As of May } 8 \text {, } \\
2020,3.75 \text { million people worldwide have had the disease, } \\
\text { and }>2,50,000 \text { have died [1]. COVID-19 presents as a mild- } \\
\text { to-moderate upper respiratory tract infection for the first } \\
\text { seven days in most cases ( } 80 \% \text { ), and approximately } 20 \% \text { of } \\
\text { patients who recover from an infection require hospitaliza- } \\
\text { tion for dyspnea, usually on days 6-8 [2]. }\end{array}$}} \\
\hline & \multicolumn{2}{|c|}{$\begin{array}{l}\text { Department of Anesthesiology, University Hospital, Kyoto } \\
\text { Prefectural University of Medicine, } 465 \text { Kajiicho, Kamigyo } \\
\text { Ward, Kyoto 602-8566, Japan }\end{array}$} & & \\
\hline & \multicolumn{2}{|c|}{$\begin{array}{l}\text { Department of Intensive Care, University Hospital, Kyoto } \\
\text { Prefectural University of Medicine, } 465 \text { Kajiicho, Kamigyo } \\
\text { Ward, Kyoto 602-8566, Japan }\end{array}$} & & \\
\hline
\end{tabular}


By severity, $81 \%$ are mild to moderate (no pneumonia or mild pneumonia), $14 \%$ severe [severe dyspnea, $\geq 30$ breaths/ min, $\leq 93 \%$ saturation of peripheral oxygen $\left(\mathrm{SpO}_{2}\right)$, partial pressure of oxygen $\left(\mathrm{PaO}_{2}\right)$ /fraction of inspiratory oxygen $\left(\mathrm{FiO}_{2}\right)<300$, and/or $>50 \%$ pulmonary infiltration within $24-48 \mathrm{~h}$ ], and $5 \%$ critical (respiratory failure, septic shock, multi-organ failure) [3].

The early identification of critically ill patients in the clinical setting is crucial because the mortality rate increases when patients with severe disease are not admitted immediately to the intensive care unit (ICU) [4, 5]. Early identification of high risk and severe COVID-19 patients leads to early treatment using intensive care by emergency doctors and, therefore important for reducing mortality [6]. Currently, blood tests and radiographic images are used for the early identification of patients with severe COVID-19 [7, 8]. However, determining the severity of the infection is sometimes difficult as examinations are limited by fear of infection among health workers. Thus, a useful index for easy identification of critically ill patients by the medical staff is needed.

We focused on pulse oximetry, an easy and non-invasive tool for identifying critically ill patients. Blood oxygen saturation measurement by pulse oximetry is simple and non-invasive and is the standard monitoring method in general wards and ICUs. Previous studies have shown that the ratio of $\mathrm{SpO}_{2}$ to $\mathrm{FiO}_{2}$ (SF ratio) is highly correlated with the $\mathrm{PaO}_{2} / \mathrm{FiO}_{2}$ ratio (PF ratio), which is used in the classification of acute respiratory distress syndrome (ARDS) severity [9]. Additionally, the clinical characteristics and outcomes (inhospital mortality and duration of mechanical ventilation) in patients with ARDS diagnosed by SF ratio showed no difference when compared with patients diagnosed by PF ratio [10]. We hypothesized that the SF ratio could be used in the early identification of patients with severe COVID-19. No reports on the use of $\mathrm{SpO}_{2}$ from pulse oximetry for the early recognition of severe COVID-19 exist. Thus, in this study, we aimed to determine whether the SF ratio at admission is useful in the early identification of patients with severe disease. We measured the SF ratio at hospital admission and compared the patient characteristics, blood test values, radiographic images, symptoms at admission, vital signs, treatments after admission, and outcomes between patients with low SF and high SF ratio.

\section{Methods}

\section{Study design}

This was a single-center, retrospective, observational study conducted at the University Hospital, Kyoto, Japan, which is a designated infectious disease hospital that treats patients with COVID-19.

\section{Study setting and population}

The subjects were patients diagnosed with COVID-19 between January 24 and May 6, 2020, based on the provisional guidelines from the World Health Organization. For the diagnosis of a COVID-19 infection, RNA was extracted from the nasopharyngeal swab of patients, and the SARS$\mathrm{CoV}-2$ gene was identified using a nucleic acid amplification test [11].

\section{Study protocol}

In this study, the severity classification of COVID-19 was based on a previously reported severity classification for ARDS [9].

\section{Measurements}

At hospital admission, SF ratio $<144$ was considered severe, 144-235, moderatem, 235-315, mild, and $\geq 315$, normal. Oxygen therapy was not provided to patients with $\mathrm{SpO}_{2} \geq 97 \%$. The patients were divided into two groups: high group (normal to mild disease) and low group (moderate to severe disease).

The $\mathrm{FiO}_{2}$ values during oxygen therapy with a nasal cannula were as follows: 0.24 for $1 \mathrm{~L}, 0.28$ for $2 \mathrm{~L}, 0.32$ for $3 \mathrm{~L}$, 0.36 for $5 \mathrm{~L}$, and 0.4 for $5 \mathrm{~L}$. With a simple oxygen mask, the values were 0.45 for $5 \mathrm{~L}, 0.5$ for $6 \mathrm{~L}, 0.55$ for $7 \mathrm{~L}$, and 0.6 for $8 \mathrm{~L}$. With an oxygen reservoir bag, the values were 0.6 for $6 \mathrm{~L}, 0.7$ for $7 \mathrm{~L}$, and 0.8 for $\geq 8 \mathrm{~L}$. The relationship between patient $\mathrm{FiO}_{2}$ and $\mathrm{SpO}_{2}$ was plotted (Fig. 1).

For all patients, data on age, sex, body mass index, sources of infection, time from symptom onset to hospitalization, medical history (hypertension, dyslipidemia, diabetes, chronic cardiac disease, chronic kidney disease, respiratory system disease, nervous system disease, liver disease, malignancy, obesity), smoking history, clinical symptoms, blood test results, chest radiographs, post-hospitalization complications, treatment methods, and outcomes were obtained from electronic medical records and nursing records. The primary outcome measure was mortality, and the secondary outcome measure was the complication incidence between admission and May 11, 2020 at the time of statistical analysis. The nine patients were still in the hospital when the data collection was completed on May 11, 2020 because they needed treatment and were undergoing isolation for COVID-19. This study was approved by the ethics committee of the University Hospital of the designated medical institutions for class I infectious diseases in Kyoto Prefecture, and written informed consent was waived 


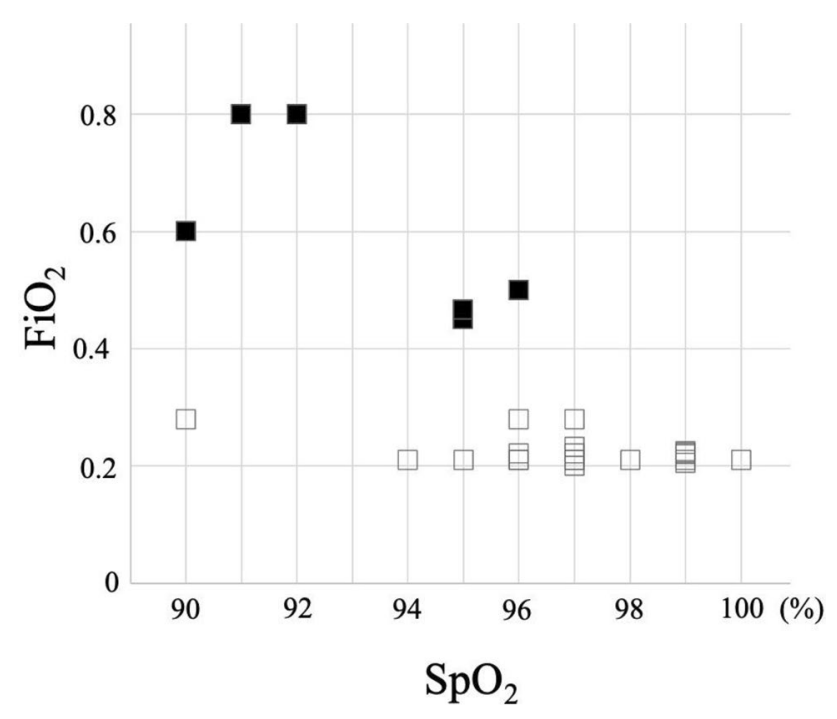

Fig. 1 Scatter plot correlation between respiratory rate and SF ratio indicates a negative correlation. Black square: the low group. White square: the high group

because of the retrospective design of the study. No subjects refused to participate in the study.

\section{Data analysis}

Continuous variables were expressed as median (interquartile range, IQR) values and compared using the Mann-Whitney $U$ test. Categorical variables were presented as numbers $(\%)$, and Fisher's exact test was used to examine the differences between the low and high groups. Spearman's rank correlation coefficient was used to assess the significance of the correlation. The tests were two-tailed, with the significance set at $\alpha<0.05$. EZR software version 1.41 (Saitama Medical Center, Jichi Medical University, Saitama, Japan) was used for all the analyses.

\section{Results}

As of May 8, 2020, 27 patients with confirmed COVID-19 infection had been admitted to the University Hospital of the Kyoto Prefectural University of Medicine. One patient who was intubated and had a severe condition at admission was excluded.

The median age of the patients was 51.5 years (IQR 35.8-67.0), and 14 (54\%) were men. Of the 26 patients, six were in the low group, and five were men. The median SF ratio of the low group was 171 (IQR 123.7-226.1). No major differences in comorbidities were found between the low and high groups ( $p>0.05$, Table 1, Fig. 2$)$. The median time from symptom onset to hospitalization was 6.0 days (IQR
4.3-8.0), a slight difference between the low and high groups was observed $(p=0.27)$.

The comorbidities included hypertension $(8 / 26,31 \%)$, dyslipidemia $(7 / 26,27 \%)$, and diabetes $(7 / 26,27 \%)$, no major differences were noted between the low and high groups $(p>0.05)$. The most common symptoms at admission were fever $(17 / 26,65 \%)$ and cough $(16 / 26,62 \%)$. Other symptoms included shortness of breath, sputum production, fatigue, and dyspnea. No major differences in symptoms were found between the low and high groups $(p>0.05)$. While all patients in the low group had a fever, no statistically significant difference was observed between the groups $(p=0.06)$.

For vital signs, the median respiratory rate was 22 breaths/min (IQR 18-26) and was significantly higher in the low group [28 breaths/min, (IQR 23-30)] than in the high group [20.5 breaths/min, $(17.5-24)](p=0.017)$. There was a slight, but not significant negative correlation between respiratory rate and $\mathrm{SF}$ ratio $(-0.45, p=0.13)$ (Fig. 3). Moreover, at admission, bilateral pneumonia was observed in chest radiographs in 13 patients $(50 \%)$ and in chest computed tomography (CT) images in 20 patients (77\%). All patients in the low group exhibited bilateral pneumonia in both chest radiographs and CT images (Table 2, Fig. 4).

At admission, compared with the high group, the low group exhibited higher leukocyte $\left[7.1 \times 10^{9} / \mathrm{L}(4.6-9.0)\right.$ vs. $\left.4.1 \times 10^{9} / \mathrm{L}(3.8-5.6), p=0.0409\right]$ and neutrophil $\left[5.8 \times 10^{9} / \mathrm{L}\right.$ (3.7-7.9) vs. $\left.2.5 \times 10^{9} / \mathrm{L}(2.3-3.5), \mathrm{p}=0.008\right]$ counts, higher C-reactive protein [CRP $15.15 \mathrm{mg} / \mathrm{L}(8.3-21.5)$ vs. $1.71(0.5-4.7), p<0.001]$, lactate dehydrogenase [LDH 483 U/L (436-527) vs. 1217 (184-254), $p<0.001]$, aspartate transaminase [AST 65.0 U/L (43.5-73.8) vs. $27.5(25.0-32.0), p=0.002$ ], alanine transaminase [ALT $41.5 \mathrm{U} / \mathrm{L}(39.5-51.8)$ vs. 20.5 (16.0-37.3), $p<0.001]$, ferritin $[1253 \mathrm{ng} / \mathrm{mL}(1153-1421)$ vs. $199(120-308), p<0.001]$ and D-dimer [1.3 $\mu \mathrm{g} / \mathrm{mL}(0.90-1.40)$ vs. $0.6(0.49-0.95)$, $p=0.008$ ] levels, (Fig. 5), and lower albumin [Alb $28 \mathrm{~g} / \mathrm{L}$ (25-30) vs. 38 (36-43), $p=0.0084$ ] level (Table 2).

Treatment after admission included antiviral agents (lopinavir/ritonavir, favipiravir) in 17 patients $(65 \%)$. In addition, $13(50 \%)$ patients received empirical antimicrobial therapy. Four patients $(15 \%)$ needed continuous renal replacement therapy and invasive positive pressure ventilation, of which one was placed on extracorporeal membrane oxygenation. These patients were all in the low group (Table 3). The median SF ratio immediately before the patients required invasive positive pressure ventilation was 115 (IQR 109-113).

In the low group, complications during hospitalization included ARDS (4 patients, 15\%), acute kidney injury (4, $15 \%)$, secondary infection $(3,12 \%)$, septic shock $(3,12 \%)$, and myocardiopathy and arrhythmia $(1,4 \%)$, these complications were not observed in the high group. Nineteen 
Table 1 Demographics and characteristics of patients diagnosed with COVID-19 at the University Hospital of the Kyoto Prefectural University of Medicine, 4 March-8 May, 2020

\begin{tabular}{|c|c|c|c|c|}
\hline & All patients $(n=26)$ & Low group $(n=6)$ & High group $(n=20)$ & $p$ value \\
\hline $\mathrm{SpO}_{2} / \mathrm{FiO}_{2}$ & $457.1[326.8-465.5]$ & $171.0[123.7-226.1]$ & $461.9[455.9-471.4]$ & $<0.01$ \\
\hline Age, years & $51.5[35.8-67.0]$ & $64.5[54.3-70.3]$ & $47.5[34.0-60.3]$ & 0.17 \\
\hline Sex, male & $14(54 \%)$ & $5(83 \%)$ & $9(45 \%)$ & 0.17 \\
\hline BMI & $22.7[20.7-24.8]$ & $23.5[21.3-24.4]$ & $22.4[20.5-25.1]$ & 0.929 \\
\hline Number of unknown sources of infection & $9(35 \%)$ & $4(67 \%)$ & $5(25 \%)$ & 0.138 \\
\hline Hospitalization from onset & $6.0[4.3-8.0]$ & $7.5[5.3-9.8]$ & $6.0[4.0-7.3]$ & 0.27 \\
\hline \multicolumn{5}{|l|}{ Comorbidity } \\
\hline Hypertension & $8(31 \%)$ & $2(33 \%)$ & $6(30 \%)$ & 1 \\
\hline Dyslipidemia & $7(27 \%)$ & $2(33 \%)$ & $5(25 \%)$ & 1 \\
\hline Diabetes & $7(27 \%)$ & $3(50 \%)$ & $4(20 \%)$ & 0.293 \\
\hline Chronic cardiac disease & 0 & - & - & \\
\hline Chronic kidney disease & 0 & - & - & \\
\hline Respiratory system disease & $6(23 \%)$ & $2(33 \%)$ & $4(20 \%)$ & 0.596 \\
\hline Nervous system disease & $5(19 \%)$ & $1(17 \%)$ & $4(20 \%)$ & 1 \\
\hline Liver disease & $3(12 \%)$ & $1(17 \%)$ & $2(10 \%)$ & 1 \\
\hline Malignancy & 0 & - & - & \\
\hline HIV/AIDS & 0 & - & - & \\
\hline Obesity (BMI > 30 kg/m2) & $2(8 \%)$ & $1(17 \%)$ & $1(5 \%)$ & 0.415 \\
\hline Smoking history & $8(31 \%)$ & $2(33 \%)$ & $6(30 \%)$ & 1 \\
\hline \multicolumn{5}{|l|}{ Symptoms and sign on admission day } \\
\hline Fever $\left(>37.5^{\circ} \mathrm{C}\right)$ & $17(65 \%)$ & $6(100 \%)$ & $11(55 \%)$ & 0.0634 \\
\hline Cough & $16(62 \%)$ & $5(83 \%)$ & $11(55 \%)$ & 0.352 \\
\hline Sputum production & $7(27 \%)$ & $1(17 \%)$ & $6(30 \%)$ & 1 \\
\hline Sore throat & $2(8 \%)$ & 0 & $2(10 \%)$ & 1 \\
\hline Fatigue & $8(31 \%)$ & $4(67 \%)$ & $4(20 \%)$ & 0.051 \\
\hline Shortness of breath & $5(19 \%)$ & $2(33 \%)$ & $3(15 \%)$ & 0.558 \\
\hline Dyspnea & $11(42 \%)$ & $4(67 \%)$ & $7(35 \%)$ & 0.348 \\
\hline Systolic pressure, $\mathrm{mmHg}$ & 119 [113-134] & $123[117-151]$ & 119 [112-134] & 0.394 \\
\hline Diastolic pressure, $\mathrm{mmHg}$ & $73[65-84]$ & $71[68-95]$ & $76[65-83]$ & 0.831 \\
\hline Heart rate (per min) & $95[84-100]$ & 89 [83-99] & $95[88-101]$ & 0.465 \\
\hline \multirow[t]{2}{*}{ Respiratory rate (per min) } & 22 [18-26] & $28[23-30]$ & $20.5[17.5-24]$ & 0.0172 \\
\hline & All patients $(n=26)$ & Low group $(n=6)$ & High group $(n=20)$ & $p$ value \\
\hline \multicolumn{5}{|c|}{ Chest X-ray findings on admission to the hospital } \\
\hline No pneumonia & $9(35 \%)$ & 0 & $9(45 \%)$ & 0.0278 \\
\hline Unilateral pneumonia & $4(15 \%)$ & 0 & $4(20 \%)$ & \\
\hline Bilateral pneumonia & $13(50 \%)$ & $6(100 \%)$ & $7(35 \%)$ & \\
\hline \multicolumn{5}{|l|}{ Chest CT findings on admission to the hospital } \\
\hline No pneumonia & $2(8 \%)$ & 0 & $2(10 \%)$ & 0.731 \\
\hline Unilateral pneumonia & $4(15 \%)$ & 0 & $4(20 \%)$ & \\
\hline Bilateral pneumonia & $20(77 \%)$ & $6(100 \%)$ & $14(70 \%)$ & \\
\hline
\end{tabular}

Data presented as median [IQR], $n(\%)$

$\mathrm{SpO}_{2}$ saturation of peripheral oxygen, $\mathrm{FiO}_{2}$ fraction of inspiratory oxygen, $\mathrm{BMI}$ body mass index, $\mathrm{HIV}$ human immunodeficiency virus, $\mathrm{AIDS}$ acquired immunodeficiency syndrome, $C T$ computed tomography

patients $(73 \%)$ had liver damage 6/6 (100\%) in the low group, whereas $13 / 20(65 \%)$ in the high group), no statistically significant difference was found between the two groups ( $p=0.146$ ). As of May 11, 2020, 15 of the 26 patients had been discharged from the hospital; two patients from the high group had died.

Currently, a treatment that directly targets the new coronavirus has not been established. Thus, symptomatic treatment, 


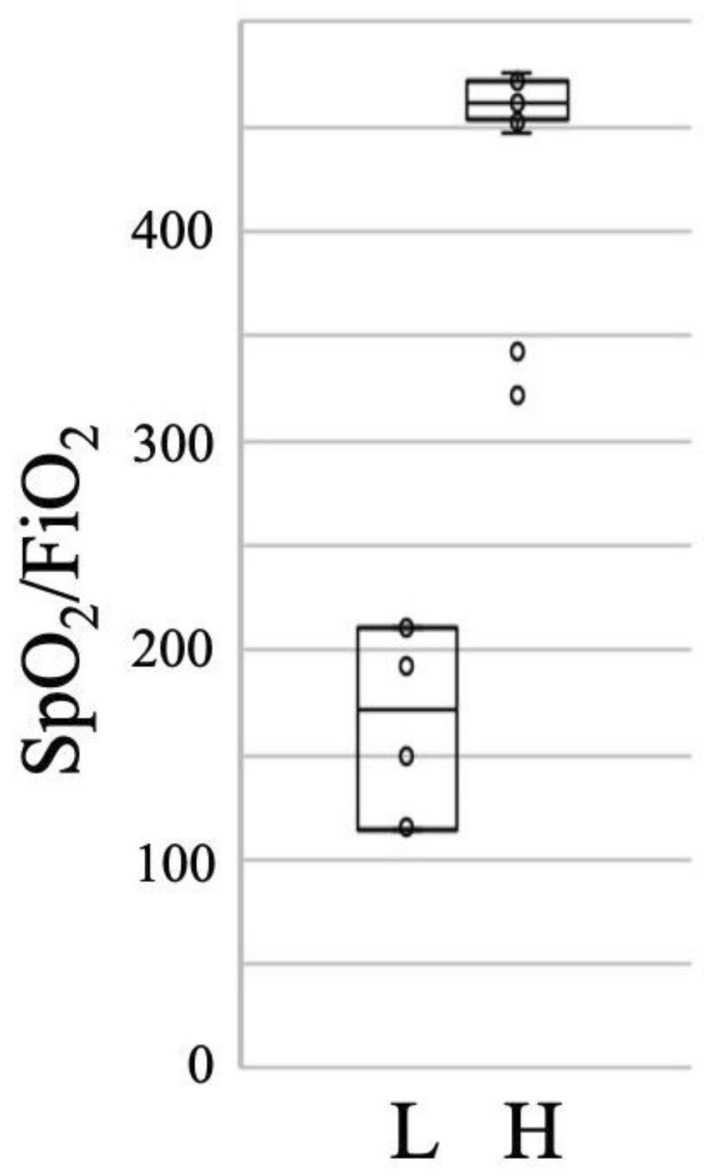

Fig. 2 Comparative bar charts of $\mathrm{SpO}_{2} / \mathrm{FiO}_{2}$ between the low group and the high group. $L$ the low group. $H$ : the high group

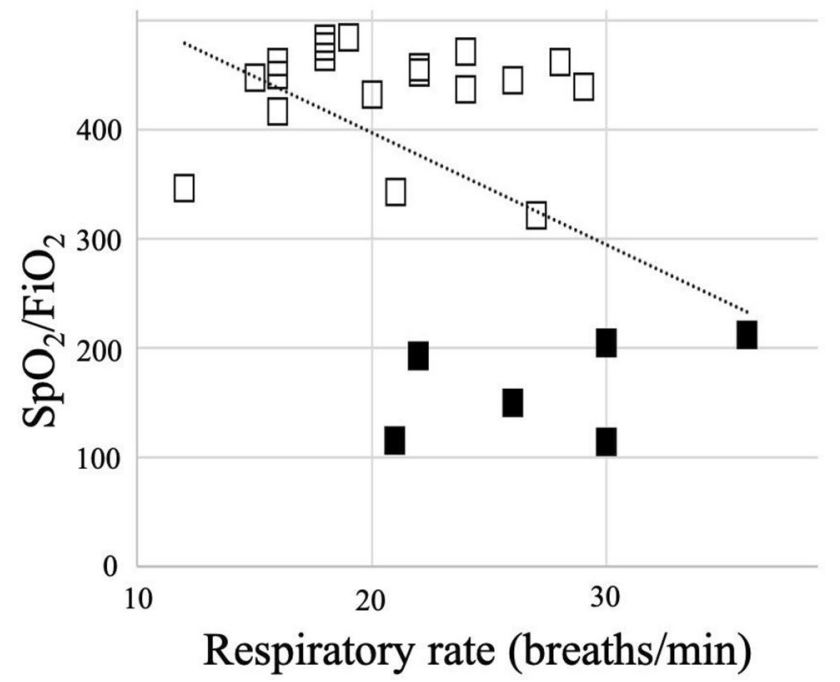

Fig. 3 Scatter plot correlation between respiratory rate and SF ratio indicates a negative correlation. Black square: the low group. White: the high group such as oxygen therapy and antipyretic drug administration, has been implemented, and it appears that virus destruction depends on the patient's immunity. However, in severe cases, symptomatic treatment only is insufficient; thus, antiviral drugs have been used to help reduce disease severity.

\section{Discussion}

In this study, we performed clinical observations to determine whether the SF ratio at admission could be used to identify disease severity in patients with COVID-19. We found that patients with moderate to high SF ratios at admission had more abnormal blood test values and more complications after hospitalization. Thus, SF ratio measurement at admission may be highly beneficial as it provides an early assessment of the severity of COVID-19 and helps identify treatment strategies. Patients with COVID-19 mainly have respiratory symptoms. Hence, using pulse oximetry, which is used to frequently measure blood oxygen saturation, we could detect changes in disease severity.

In several other studies, $15.7-31 \%$ of patients had severe disease. $[7,12,13]$. In our study, $23 \%$ of the patients were in the low group (severe cases) at admission, and the overall median age and prevalence rate were similar to those in the reports from China $[14,15]$. The proportion of patients with hypertension, which is the most common comorbidity, was $31 \%$, which is similar to that in a previous report. No significant difference in hypertension rates between the two groups in our study was found. In contrast, the number of patients with hypertension was significantly higher in the severe disease group than in the non-severe disease group in a previous study [16]. Hypertension, obesity, diabetes mellitus, and heart disease were regarded as important underlying diseases, and patients who were prone to severe disease were characterized by older age, male sex, and smoking. These underlying disorders are the same as coronary risk factors that worsen atherosclerotic disease [17]. In critically ill patients, SARS-CoV2 binds to angiotensin-converting enzyme two receptors on vascular endothelial cells, impairing vascular endothelial glycocalyx, an extracellular matrix that covers vascular endothelial cells throughout the body, and reducing vascular endothelial cell function [16]. This is thought to facilitate the invasion and proliferation of SARS-CoV2.

The clinical symptoms of COVID-19 are non-specific and difficult to distinguish from the common cold, and they are extremely similar to those of Middle East respiratory syndrome (MERS) and severe acute respiratory syndrome (SARS) [18]. In patients with COVID-19, fever is observed in $88.7 \%$ of cases, cough in $67.8 \%$, fatigue in $38.1 \%$, and sputum production in $33.7 \%$ [12]. In our study, the frequencies of cough, fatigue, and sputum production were similar 
Table 2 Laboratory findings of patients diagnosed with COVID-19 on hospital admission

\begin{tabular}{|c|c|c|c|c|}
\hline Laboratory values on hospital admission & All patients $(n=26)$ & Low group $(n=6)$ & High group $(n=20)$ & $p$ value \\
\hline Blood leukocyte count $(10 \times 9 / \mathrm{L})$ & $4.4[3.8-5.7]$ & $7.1[4.6-9.0]$ & $4.1[3.8-5.6]$ & 0.0409 \\
\hline Neutrophil $(10 \times 9 / \mathrm{L})$ & $3.3[2.3-4.3]$ & $5.8[3.7-7.9]$ & $2.5[2.3-3.5]$ & 0.0081 \\
\hline Lymphocyte count $(10 \times 9 / \mathrm{L})$ & $0.9[0.7-1.4]$ & $0.7[0.5-0.7]$ & $1.0[0.8-1.4]$ & 0.055 \\
\hline Platelet count $(10 \times 9 / \mathrm{L})$ & $190[155-244]$ & $190[151-243]$ & $190[156-228]$ & 0.976 \\
\hline C-reactive protein $(\mathrm{mg} / \mathrm{L})$ & $3.15[0.54-6.22]$ & $15.15[8.3-21.5]$ & $1.71[0.5-4.7]$ & 0.000909 \\
\hline Lactate dehydrogenase (U/L) & 237 [195-379] & 483 [436-527] & $217[184-254]$ & 0.000104 \\
\hline BUN (mg/dL) & $11.8[9.9-15.8]$ & $11.7[9.6-17.3]$ & $11.8[10.0-15.3]$ & 0.976 \\
\hline Creatinine (mg/dL) & $0.79[0.62-0.97]$ & $0.89[0.68-0.93]$ & $0.72[0.63-0.97]$ & 0.855 \\
\hline Aspartate aminotransferase (U/L) & $29.5[25.3-45.8]$ & $65.0[43.5-73.8]$ & $27.5[25.0-32.0]$ & 0.00231 \\
\hline Alanine aminotransferase (U/L) & $24.5[17.0-40.5]$ & $41.5[39.5-51.8]$ & $20.5[16.0-37.3]$ & 0.0115 \\
\hline Albumin (g/L) & $37[34-42]$ & 28 [25-30] & $38[36-43]$ & 0.000447 \\
\hline Ferritin $(\mathrm{ng} / \mathrm{mL})$ & 274 [147-719] & 1253 [1153-1421] & 199 [120-308] & $1.98 \mathrm{E}-05$ \\
\hline D-Dimer $(\mu \mathrm{g} / \mathrm{mL}) *$ & 0.70 [0.49-1.13] & $1.3[0.90-1.40]$ & $0.6[0.49-0.95]$ & 0.00849 \\
\hline
\end{tabular}

Data presented as median [IQR]

$B U N$ blood urea nitrogen

*Date available for 24 patients

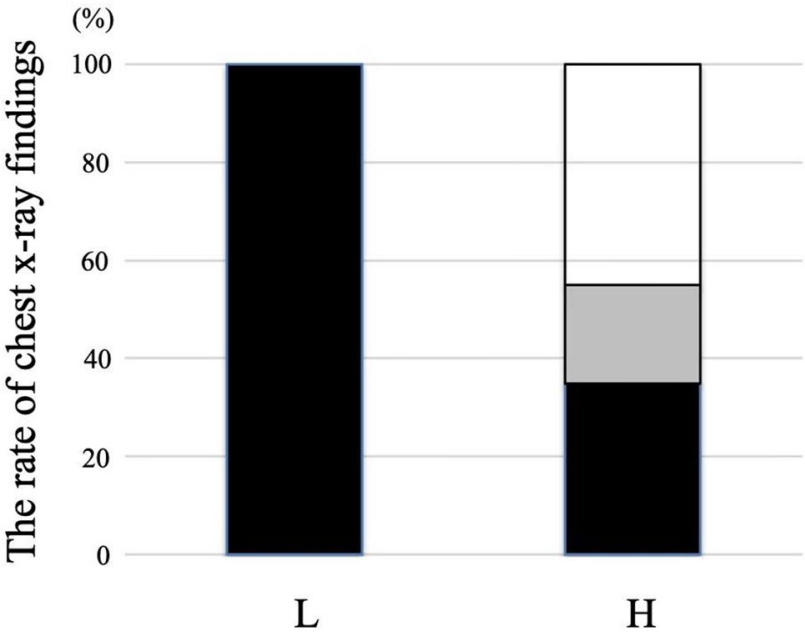

Fig. 4 The rate of chest X-ray findings on admission. Bar graph for comparison of chest X-ray pneumonia on admission to the hospital between groups. Black square: bilateral pneumonia. Gray square: unilateral pneumonia. White square: no pneumonia

to those in previous reports, whereas the number of patients with fever was lower in our study (65\%). This underscores the fact that infected patients can be asymptomatic.

Moreover, in our study, no difference in symptoms at admission between patients with high and low disease severity was observed, which is consistent with the finding of a previous study [12]. This indicates the difficulty in diagnosing COVID-19 and determining disease severity based on symptoms alone. In addition, regarding vital signs, the median respiratory rate at admission was 22 breaths/min, with the more severe patients exhibiting higher breaths per minute. COVID-19 is primarily a lung infection, thereby making the respiratory organs the most vulnerable to symptoms. A previous study showed that $17.3 \%$ of inpatients had a respiratory rate $>$ breaths/min [16].

Furthermore, all severe patients with COVID-19 exhibited bilateral pneumonia at admission on both chest radiographs and CT images. [19, 20]. Pneumonia severity classification can be determined by the CURB- 65 recommended by the British Thoracic Society [21], or by the pneumonia severity index recommended by the American Society of Infectious Diseases [22], which include blood tests.

Abnormal values have been observed in hematological tests, such as high leukocyte, neutrophil, and lymphocyte counts and low platelet count; in biochemical tests, such as low albumin level and high LDH, blood urea nitrogen (BUN), creatinine, AST, and ALT levels; in coagulation tests, such as D-dimer assessments; and in inflammatory biomarker evaluations, such as high CRP and serum ferritin levels. These results have been correlated with severe disease and death [14, 23, 24]. Moreover, elevated procalcitonin (PCT) and ALT levels have been reported to be independent risk factors for death in a multivariate Cox regression analysis [25]. Abnormalities in coagulation function have been reported not only in COVID-19 but also in SARS and MERS. The mortality rate of patients with COVID-19 increases when the D-dimer level on admission is $2.0 \mu \mathrm{g} /$ $\mathrm{ml}$ or more [26]. In our study, the low group exhibited significantly higher leukocyte and neutrophil counts; lower albumin level, and higher LDH, AST, ALT, CRP, serum ferritin and D-dimer levels both immediately after admission and for the worst post-admission value. In addition, the low group also exhibited a significantly lower lymphocyte count 
Fig. 5 Comparative bar charts of blood test results between the low group and the high group. $C R P$ C-reactive protein, $L D H$ lactate dehydrogenase, $A S T$ aspartate transaminase, $A L T$ alanine transaminase
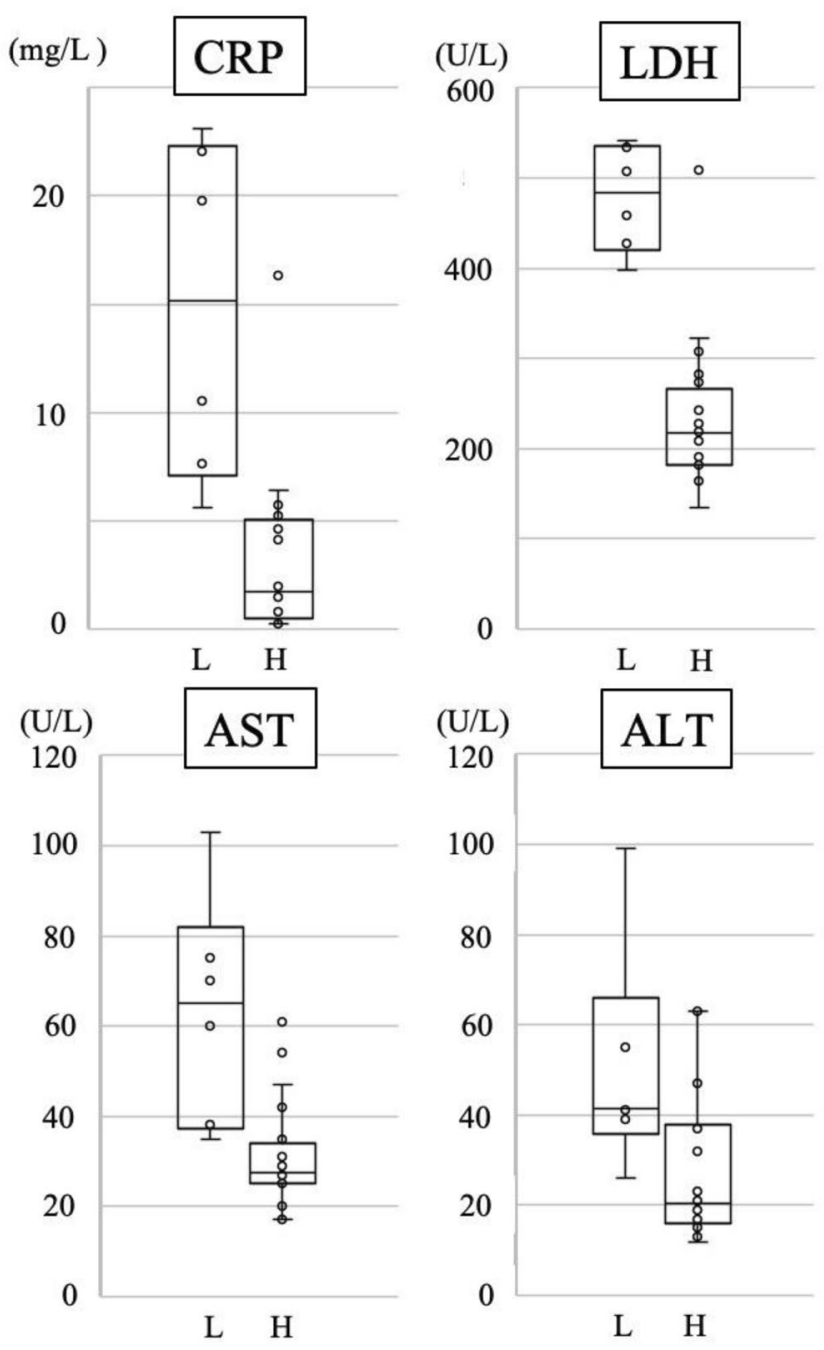

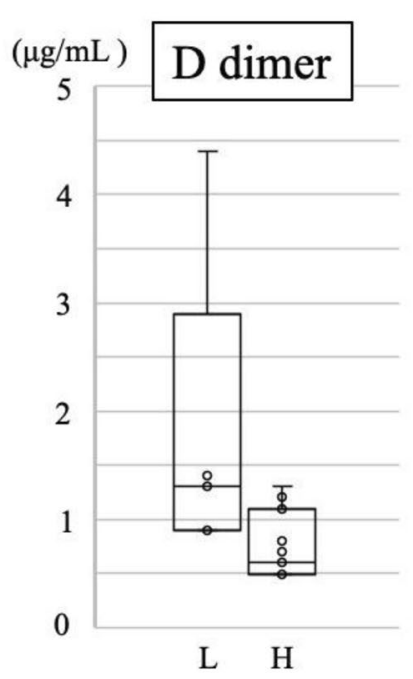

for the worst post-admission value. Elevated leukocytes and neutrophil counts and CRP were considered to be associated with severe inflammation, elevated LDH, AST, and ALT was considered to be associated with organ damage, and elevated D-dimer was considered to be associated with a high thrombotic tendency. In recent years, it has been suspected that COVID-19 patients suffer from systemic inflammatory-reactive microvascular endotheliopathy. The primary mechanism is characterized by thrombotic microvascular disease, loss of vascular endothelial glycocalyx, and increased vascular permeability [27].

After admission, 17 patients $(65 \%)$ received antiviral therapy, including all members of the low group. As a definite treatment option for patients with COVID-19 remains to be clearly established, doctors may administer antiviral agents to the patients with a more severe disease. Clinical trials that evaluate the effectiveness of antiviral agents are underway [28]. In addition, 13 patients (50\%) received antibiotic therapy, which covered both common bacterial infections and atypical pneumonia; however, three patients
$(50 \%)$ in the low group had secondary infections. Bacterial infections have been reported in $50 \%$ of patients with severe COVID-19 [29]. ICUs can be breeding grounds of resistant bacteria; thus, concerns regarding antibacterial use encouraging the growth of resistant bacteria have been raised.

Further, while high-flow nasal oxygen therapy, which we did not adopt, could increase the risk of aerosol infection, previous studies have demonstrated that early application of a high-flow nasal cannula may help avoid intubation among patients with ARDS [30, 31]. Regarding complications, ARDS may be considered when a patient's condition becomes severe, as was observed in our study. Patients may also be at risk for acute kidney injury [29].

Patients with pneumonia commonly develop heart complications, such as new or worsening heart failure, arrhythmia, and myocardial infarction; cardiac arrest occurs in approximately $3 \%$ of inpatients with pneumonia who require ICU admission [32]. In our study, one patient who developed myocardiopathy and an arrhythmia died. Using SF ratios, early identification of not only COVID-19-induced lung 
Table 3 Treatments, complications, and outcomes of patients diagnosed with COVID-19

\begin{tabular}{|c|c|c|c|c|}
\hline Treatments & All patients $(n=26)$ & Low group $(n=6)$ & High group $(n=20)$ & $p$ value \\
\hline Invasive mechanical ventilation & $4(15 \%)$ & $4(68 \%)$ & 0 & 0.001 \\
\hline Antiviral treatment & $17(65 \%)$ & $6(100 \%)$ & $11(55 \%)$ & 0.0634 \\
\hline Inhaled steroid & $7(27 \%)$ & $4(67 \%)$ & $3(15 \%)$ & 0.0278 \\
\hline Antimalarial drug & $5(19 \%)$ & $5(83 \%)$ & 0 & $9.12 \mathrm{E}-05$ \\
\hline Antibiotic treatment & $13(50 \%)$ & $5(83 \%)$ & $8(40 \%)$ & 0.16 \\
\hline Continuous renal replacement therapy & $4(15 \%)$ & $4(67 \%)$ & 0 & 0.001 \\
\hline Extracorporeal membrane oxygenation & $1(4 \%)$ & $1(17 \%)$ & 0 & - \\
\hline \multicolumn{5}{|l|}{ Complications } \\
\hline ARDS & $4(15 \%)$ & $4(68 \%)$ & 0 & $1.00 \mathrm{E}-03$ \\
\hline Acute renal injury & $4(15 \%)$ & $4(68 \%)$ & 0 & 0.00465 \\
\hline Acute cardiac injury & $1(4 \%)$ & $1(17 \%)$ & 0 & - \\
\hline Liver dysfunction & $19(73 \%)$ & $6(100 \%)$ & $13(65 \%)$ & 0.146 \\
\hline Secondary infection & $3(12 \%)$ & $3(50 \%)$ & 0 & 0.00769 \\
\hline Septic shock & $3(12 \%)$ & $3(50 \%)$ & 0 & 0.00769 \\
\hline \multicolumn{5}{|l|}{ Clinical outcomes } \\
\hline Hospitalization & $9(34 \%)$ & $3(50 \%)$ & $6(30 \%)$ & 0.628 \\
\hline Discharge & $15(58 \%)$ & $1(17 \%)$ & $14(70 \%)$ & 0.0538 \\
\hline Death & $2(8 \%)$ & $2(33 \%)$ & 0 & 0.0462 \\
\hline
\end{tabular}

Data presented as $n(\%)$

$A R D S$ acute respiratory distress syndrome

damage but also concomitant sepsis, secondary infections, kidney damage, liver damage, and myocardial damage was possible.

\section{Limitations}

First, this is a retrospective study with a short study period. Second, there was an imbalance of data between the two groups, and both the low and high groups had small sample sizes. Because this was an exploratory data analysis, not based on a formal hypothesis, we did not calculate sample sizes. Third, hormonal imbalances not tested at admission may have affected the disease risk and severity. Clinical trials with larger sample sizes should be conducted in the future.

\section{Conclusion}

To our knowledge, this was the first study on the use of the SF ratio upon hospital admission for the detection of severe COVID-19 pneumonia. Early identification of severe COVID-19 using the SF ratio may lead to early ICU admission and, thus, treatment by emergency and intensive care physicians.
Acknowledgements We gratefully acknowledge all medical personnel involved in the treatment of patients with COVID-19.

Author contributions MS: conceptualization, methodology, software, validation, formal analysis, data curation, writing-original draft, writing-review and editing, visualization, supervision. SH: conceptualization, methodology, writing - review and editing, supervision, project administration. All authors reviewed and approved the submitted manuscript.

Funding This research did not receive any specific grant from funding agencies in the public, commercial, or not-for-profit sectors.

Availability of data and materials All data generated or analyzed during this study are included in this published article.

\section{Declarations}

Conflict of interest MS, YK, TY, BO, and SH report no conflict of interest.

Ethical approval This study was approved by the ethics committee of the University Hospital of the Kyoto Prefectural University of Medicine (ERB-C-1711).

Informed consent Informed consent was obtained in the form of optout on the website for publication of this study. 


\section{References}

1. CDC. Coronavirus disease 2019 (COVID-19) Situation Report 2020. https://www.who.int/docs/default-source/coronaviruse/ situation-reports/20200508covid-19-sitrep-109.pdf?sfvrsn=68f2c 632_6, 2020. Accessed on 8 May 2020.

2. Bouadma L, Lescure FX, Lucet JC, Yazdanpanah Y, Timsit JF. Severe SARS-CoV-2 infections: practical considerations and management strategy for intensivists. Intensive Care Med. 2020;46:579-82.

3. Wu Z, McGoogan JM. Characteristics of and important lessons from the coronavirus disease 2019 (COVID-19) outbreak in China: summary of a report of 72314 cases from the Chinese Center for Disease Control and Prevention. JAMA. 2020;323:1239-42.

4. Young MP, Gooder VJ, McBride K, James B, Fisher ES. Inpatient transfers to the intensive care unit: delays are associated with increased mortality and morbidity. J Gen Intern Med. 2003;18:77-83.

5. Churpek MM, Wendlandt B, Zadravecz FJ, Adhikari R, Winslow $\mathrm{C}$, Edelson DP. Association between intensive care unit transfer delay and hospital mortality: a multicenter investigation. J Hosp Med. 2016;11:757-62.

6. Sun Q, Qiu H, Huang M, Yang Y. Lower mortality of COVID-19 by early recognition and intervention: experience from Jiangsu Province. Ann Intensive Care. 2020;10:33.

7. Huang C, Wang Y, Li X, Ren L, Zhao J, Hu Y, Zhang L, Fan G, Xu J, Gu X, Cheng Z, Yu T, Xia J, Wei Y, Wu W, Xie X, Yin W, Li H, Liu M, Xiao Y, Gao H, Guo L, Xie J, Wang G, Jiang R, Gao Z, Jin Q, Wang J, Cao B. Clinical features of patients infected with 2019 novel coronavirus in Wuhan. China Lancet. 2020;395:497-506.

8. Lyu P, Liu X, Zhang R, Shi L, Gao J. The performance of chest CT in evaluating the clinical severity of COVID-19 pneumonia: identifying critical cases based on CT characteristics. Invest Radiol. 2020;55:412-21.

9. Rice TW, Wheeler AP, Bernard GR, Hayden DL, Schoenfeld DA, Ware LB. National Institutes of Health, National Heart, Lung, and Blood Institute ARDS Network, comparison of the $\mathrm{SpO} 2 / \mathrm{FIO} 2$ ratio and the $\mathrm{PaO} 2 / \mathrm{FIO} 2$ ratio in patients with acute lung injury or acute respiratory distress syndrome. Chest. 2007;132:410-7.

10. Chen W, Janz DR, Shaver CM, Bernard GR, Bastarache JA, Ware LB. Clinical characteristics and outcomes are similar in ARDS diagnosed by oxygen saturation/FiO2 ratio compared with $\mathrm{Pao} 2 /$ Fio2 Ratio. Chest. 2015;148:1477-83.

11. Okamaoto K, Shirato K, Nao N, Saito S, Kageyama T, Hasegawa H, Suzuki T, Matsuyama S, Takeda M. An assessment of realtime RT-PCR kits for SARS-CoV-2 detection. Jpn J Infect Dis. 2020;73(5):366-8.

12. Guan WJ, Ni ZY, Hu Y, Liang WH, Ou CQ, He JX, Liu L, Shan H, Lei CL, Hui DSC, Du B, Li LJ, Zeng G, Yuen KY, Chen RC, Tang CL, Wang T, Chen PY, Xiang J, Li SY, Wang JL, Liang ZJ, Peng YX, Wei L, Liu Y, Hu YH, Peng P, Wang JM, Liu JY, Chen Z, Li G, Zheng ZJ, Qiu SQ, Luo J, Ye CJ, Zhu SY, Zhong NS. China Medical Treatment Expert Group for Covid-19, clinical characteristics of coronavirus disease 2019 in China. N Engl J Med. 2020;382:1708-20.

13. Wang D, Hu B, Hu C, Zhu F, Liu X, Zhang J, Wang B, Xiang $\mathrm{H}$, Cheng Z, Xiong Y, Zhao Y, Li Y, Wang X, Peng Z. Clinical characteristics of 138 hospitalized patients with 2019 novel coronavirus-infected pneumonia in Wuhan. China JAMA. 2020;323:1061-9.

14. Chen N, Zhou M, Dong X, Qu J, Gong F, Han Y, Qiu Y, Wang J, Liu Y, Wei Y, Xia J, Yu T, Zhang X, Zhang L. Epidemiological and clinical characteristics of 99 cases of 2019 novel coronavirus pneumonia in Wuhan, China: a descriptive study. Lancet. 2020;395:507-13.

15. LiuXingBingXueZaZhi Z, Epidemiology Working Group for NCIP Epidemic Response, Chinese Center for Disease Control and Prevention. The epidemiological characteristics of an outbreak of 2019 novel coronavirus diseases (COVID-19) in China. Natl Libr Med. 2020;41(2):145-51.

16. Wang D, Hu B, Hu C, Zhu F, Liu X, Zhang J, Wang D, Hu B, Hu C, Zhu F, Liu X, Zhang J, Wang B, Xiang H, Cheng Z, Xiong Y, Zhao Y, Li Y, Wang X, Peng Z. Clinical characteristics of 138 hospitalized patients with 2019 novel coronavirus-infected pneumonia in Wuhan. China JAMA. 2020;232:1061-9.

17. Cosgun ZC, Fels B, Kusche-Vihrog K. Nanomechanics of the Endothelial Glycocalyx: From Structure to Function. Am J Pathol. 2020;190(4):732-41.

18. Assiri A, Al-Tawfiq JA, Al-Rabeeah AA, Al-Rabiah FA, AlHajjar S, Al-Barrak A, Flemban H, Al-Nassir WN, Balkhy HH, Al-Hakeem RF, Makhdoom HQ, Zumla AI, Memish ZA. Epidemiological, demographic, and clinical characteristics of 47 cases of Middle east respiratory syndrome coronavirus disease from Saudi Arabia: a descriptive study. Lancet Infect Dis. 2013;13:752-61.

19. Yang W, Cao Q, Qin L, Wang X, Cheng Z, Pan A, Dai J, Sun Q, Zhao F, Qu J, Yan F. Clinical characteristics and imaging manifestations of the 2019 novel coronavirus disease (COVID-19): a multi-center study in Wenzhou City, Zhejiang. China J Infect. 2020;80:388-93.

20. Hu Z, Song C, Xu C, Jin G, Chen Y, Xu X, Ma H, Chen W, Lin Y, Zheng Y, Wang J, Hu Z, Yi Y, Shen H. Clinical characteristics of 24 asymptomatic infections with COVID-19 screened among close contacts in Nanjing. China Sci China Life Sci. 2020;63:706-11.

21. Lim WS, van der Eerden MM, Laing R, Boersma WG, Karalus N, Town GI, Lewis SA, Macfarlane JT. Defining community acquired pneumonia severity on presentation to hospital: an international derivation and validation study. Thorax. 2003;58:377-82.

22. Fine MJ, Auble TE, Yealy DM, Hanusa BH, Weissfeld LA, Singer DE, Coley CM, Marrie TJ, Kapoor WN. A prediction rule to identify low-risk patients with community-acquired pneumonia. $\mathrm{N}$ Engl J Med. 1997;336:243-50.

23. Henry BM, de Oliveira MHS, Benoit S, Plebani M, Lippi G. Hematologic, biochemical and immune biomarker abnormalities associated with severe illness and mortality in coronavirus disease 2019 (COVID-19): a meta-analysis. Clin Chem Lab Med. 2020;58:1021-8.

24. Chen R, Liang W, Jiang M, Guan W, Zhan C, Wang T, Tang C, Sang L, Liu J, Ni Z, Hu Y, Liu L, Shan H, Lei C, Peng Y, Wei L, Liu Y, Hu Y, Peng P, Wang J, Liu J, Chen Z, Li G, Zheng Z, Qiu S, Luo J, Ye C, Zhu S, Liu X, Cheng L, Ye F, Zheng J, Zhang N, Li Y, He J, Li S, Zhong N. Medical Treatment Expert Group for COVID-19, Risk factors of fatal outcome in hospitalized subjects with coronavirus disease 2019 from a nationwide analysis in China. Chest. 2020;158(1):97-105.

25. Bao J, Li C, Zhang K, Kang H, Chen W, Gu B. Comparative analysis of laboratory indexes of severe and non-severe patients infected with COVID-19. Clin Chim Acta. 2020;509:180-94.

26. Giannis D, Ziogas IA, Gianni P. Coagulation disorders in coronavirus infected patients: COVID-19, SARS-CoV-1 MERS-CoV and lessons from the past. J Clin Virol. 2020. https://doi.org/10. 1016/j.jcv.2020.104362.

27. Yamaoka-Tojo M. Vascular endothelial glycocalyx damage in COVID-19. Int J Mol Sci. 2020;21(24):9712.

28. United States National Library of Medicine. Adaptive COVID-19 Treatment Trial (ACTT). Bethesda (MD): US National Library of Medicine. https://clinicaltrials.gov/ct2/show/NCT04280705, 2020. Accessed on 23 Apr 2020. 
29. Zhou F, Yu T, Du R, Fan G, Liu Y, Liu Z, Xiang J, Wang Y, Song B, Gu X, Guan L, Wei Y, Li H, Wu X, Xu J, Tu S, Zhang Y, Chen H, Cao B. Clinical course and risk factors for mortality of adult inpatients with COVID-19 in Wuhan, China: a retrospective cohort study. Lancet. 2020;395:1054-62.

30. Ding L, Wang L, Ma W, He H. Efficacy and safety of early prone positioning combined with HFNC or NIV in moderate to severe ARDS: a multi-center prospective cohort study. Crit Care. 2020;24(1):28

31. Messika J, Ahmed KB, Gaudry S, Miguel-Montanes R, Rafat C, Sztrymf B, Dreyfuss D, Ricard JD. Use of high-flow nasal cannula oxygen therapy in subjects with ARDS: a 1 year observational study. Respir Care. 2015;60:162-9.

32. Marrie TJ, Shariatzadeh MR. Community-acquired pneumonia requiring admission to an intensive care unit: a descriptive study. Medicine (Baltimore). 2007;86:103-11.

Publisher's Note Springer Nature remains neutral with regard to jurisdictional claims in published maps and institutional affiliations. 